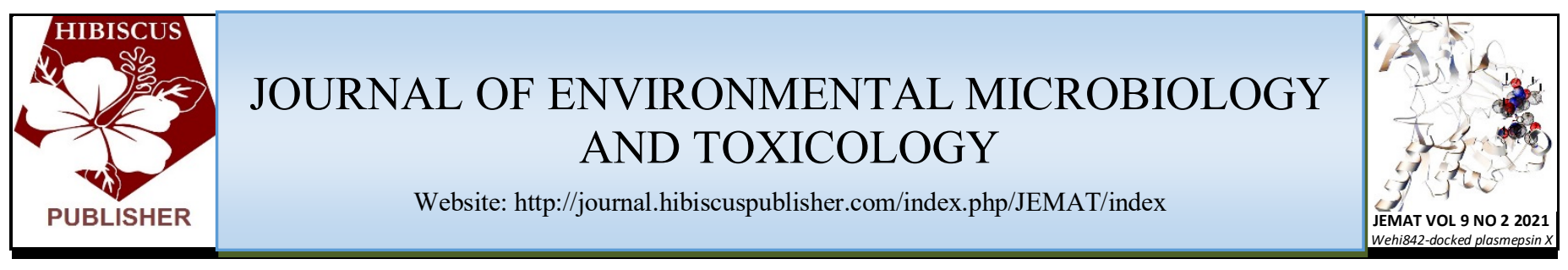

\title{
Kinetics Modelling of Pseudomonas stutzeri strain DN2 Growth Behaviour in Tributyltin Chloride
}

\author{
Abdussamad Abubakar ${ }^{1 *}$, Garba $\mathrm{Uba}^{2}$ and Hadiza Aliyu Biu ${ }^{3}$ \\ ${ }^{1}$ Department of Microbiology, Faculty of Science, Bauchi State University, Gadau, PMB 65, Nigeria. \\ ${ }^{2}$ Department of Science Laboratory Technology, College of Science and Technology, Jigawa State Polytechnic, Dutse, \\ PMB 7040, Nigeria. \\ ${ }^{3}$ National Commission for Colleges of Education P.M.B 0394 Garki, Abuja, Nigeria.
}

\author{
*Corresponding author: \\ Abdussamad Abubakar, \\ Department of Microbiology, \\ Faculty of Science, \\ Bauchi State University, \\ Gadau, PMB 65, \\ Nigeria.
}

Email: abdussamad277@gmail.com

\section{HISTORY}

Received: $14^{\text {th }}$ Oct 2021

Received in revised form: $4^{\text {th }}$ Dec 2021 Accepted: $15^{\text {th }}$ Dec 2021

\section{KEYWORDS}

Pseudomonas stutzeri

tributyltin chloride-degrading

Growth kinetics

Inhibitory kinetics

Bioremediation

\begin{abstract}
A predictive model was performed to describe Pseudomonas stutzeri strain DN2 growth behaviour in tributyltin chloride, using primary Modelling and a polynomial model as a secondary predictive model. In this investigation, data predicted using the modified Logistic (ML) was the most accurate. The Bias Factor (Bf) and Accuracy Factor (Af) values for the (ML) model were 1.39 and 1.51 , indicating that the predictions were within a reliable range. The low RMSE value of $0.14, R^{2}$ and adj $R^{2}(0.99)$ value closer to 1 , showing that modified logistics is better than the other models at describing the growth behaviour of Pseudomonas stutzeri strain DN2 in toxic tributyltin chloride. Both the Aiba and Haldane models on the other hand, among the secondary model best fit the behaviours having low RMSE and MSE values and $a d j R^{2}$ value closer to 1. In this study, the primary and secondary kinetics of Pseudomonas stutzeri strain DN2 growth behaviour in tributyltin chloride was explored and it was shown in this study that the modified logistic and the Haldane models better suit the growth behavior of Pseudomonas stutzeri strain DN2 in tributyltin chloride. The parameters obtained from the modelling exercise will be very valuable in transferring the laboratory results to the field.
\end{abstract}

\section{INTRODUCTION}

Organotin compounds are chemical compounds based on tin with hydrocarbon substituents. Organotin chemistry is part of the wider field of organometallic chemistry. Antifouling coatings for boats, wood preservatives, biocides, and plastic stabilizers are just a few of the industrial items that contain tributyltin chloride [1]. According to extensive study, tributyltin chloride is the most poisonous organotin compound known to aquatic ecosystems among the organotin compounds [2,3]. Organotin compounds' biocidal qualities make tributyltin chloride a potential ecological danger to non-target organisms in aquatic habitats [4]. It has been discovered to be particularly poisonous to several aquatic creatures, causing imposex in female molluscs and hardening of shells in oysters, even at nanometre concentrations in water [5 6]. In humans, tributyltin chloride has been found as an immune system inhibitor and endocrine disruptor. Because of its high specific gravity, tributyltin chloride is swiftly evacuated from the water column and sticks to sediments in the aquatic environment (i.e. 1.2). Its low water solubility (less than $10 \mathrm{mg} / \mathrm{L}$ at $20^{\circ} \mathrm{C}$ and $\mathrm{pH} 7$ ) explains its high binding to suspended particle organic and inorganic elements in aquatic sediment.

The rate of tributyltin chloride breakdown in sediments is shown to be much slower than in water columns. Tributyltin chloride has a half-life of 0.91 to 5.2 years in marine sediments, according to previous research [7]. Tributyltin chloride is known to be very toxic to both prokaryotes and eukaryotes, whereas the mono-, di-, and tetra-organotins are either non-toxic or slightly poisonous, and appear to cause toxicity through interacting with membrane lipids [8,9]. Abiotic mechanisms such as chemical cleavage, thermal cleavage, and UV irradiation have been described in nature to change tributyltin chloride into less hazardous molecules $\left(\mathrm{DBTCl}_{2}\right.$ and $\left.\mathrm{MBTCl}_{3}\right)$. Although tributyltin chloride is highly toxic to the majority of microbes, some natural microbial strains can survive at very high 
concentrations of tributyltin chloride using a variety of protective biochemical and molecular genetic mechanisms $[6,10]$. Several mechanisms involved in tributyltin chloride resistance in bacteria include (i) exclusion of the compound from the cell mediated by the multidrug efflux pump (ii) degradation/metabolic utilization as a carbon source [11]; (iii) bioaccumulation into the cell without the compound being broken down [12] and (iv) unique morphological alteration in the form of long inter-connected chains of bacterial cells on exposure to TBTCl [13].

This distinguishes tributyltin chloride-resistant microbes, including bacteria, as an ideal biological tool for bioremediation of tributyltin chloride contaminated sites and thus for polluted environment restoration. Ayanda, Clark and Dowson et al., [1416] believed that bacteria, algae, and fungi biotransform tributyltin chloride by sequential debutylation processes from tributyltin chloride, dibutyltin chloride $\mathrm{MBTCl}_{3}$ inorganic tin via $\beta$-hydroxylation with suitable dioxygenases $[15,16]$. Due to the fact that microbial degradation is the most common biological process for the breakdown of tributyltin chloride in coastal waters $[14,17]$, it is critical and fascinating to investigate the transformation of tributyltin chloride mediated by bacteria that thrive in such environments.

In this study, the primary and secondary kinetics of Pseudomonas stutzeri strain DN2 growth behaviour in tributyltin chloride was explored.

\section{MATERIALS AND METHODS}

Data for the primary and secondary Kinetics Modelling of Pseudomonas stutzeri strain DN2 growth behaviour in tributyltin chloride was acquired from Dnyanada et al., (2014) using WebplotDigitizer [18], which helps to digitize scanned plots into table of data with good enough precision.

\section{Statistical analysis}

Statistical significant difference between the models was calculated through various methods including the adjusted coefficient of determination $\left(R^{2}\right)$, accuracy factor (AF), bias factor (BF), Root-Mean-Square Error (RMSE) and corrected AICc (Akaike Information Criterion) as before [19].

The RMSE was calculated according to Eq. (1), where $P d_{i}$ are the values predicted by the model and $O b_{i}$ are the experimental data, $n$ is the number of experimental data, and $p$ is the number of parameters of the assessed model.

$R M S E=\sqrt{\frac{\sum_{i=1}^{n}\left(P d_{i}-O b_{i}\right)^{2}}{n-p}}$

(Eqn. 1)

The adjusted $R^{2}$ is used to calculate the quality of nonlinear models according to the formula where RMS is Residual Mean Square and $S_{y}^{2}$ is the total variance of the $y$-variable and calculated as follows.

Adjusted $\left(R^{2}\right)=1-\frac{R M S}{s_{Y}^{2}}$

$\operatorname{Adjusted}\left(R^{2}\right)=1-\frac{\left(1-R^{2}\right)(n-1)}{(n-p-1)}$

(Eqn. 3)
The Akaike information criterion (AIC) [[20] was calculated as follows;

$A I C c=2 p+n \ln \left(\frac{R S S}{n}\right)+2(p+1)+\frac{2(p+1)(p+2)}{n-p-2}$

Where $n$ is the number of data points and $p$ is the number of parameters of the model. The model with the smallest AICc value is highly likely correct [21].

Accuracy Factor (AF) and Bias Factor (BF) as suggested by Ross [22] were calculated as follows;

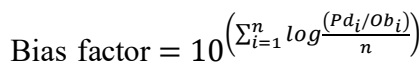

Accuracy factor $=10^{\left(\sum_{i=1}^{n} \log \frac{\left|\left(P d_{i} / O b_{i}\right)\right|}{n}\right)}$

\section{Fitting of the data}

The data fitting of Pseudomonas stutzeri strain DN2 growth behaviour in tributyltin chloride using various growth models (Table 1 and 2), Curve Expert Professional software was used to fit the nonlinear equations to growth data using nonlinear regression with a Marquardt algorithm that minimizes sums of square residuals (Version 1.6). This is a strategy for minimizing the sum of squares of differences between predicted and measured values. The program calculates the steepest slope of the curve between four datum points (estimation of max), intersects this line with the $\mathrm{x}$ axis (estimation of), and uses the final datum point as an estimate for the asymptote (A). Because Huang's model is a differential equation, it must be solved numerically.

Table 1. Primary kinetic models used in this study.

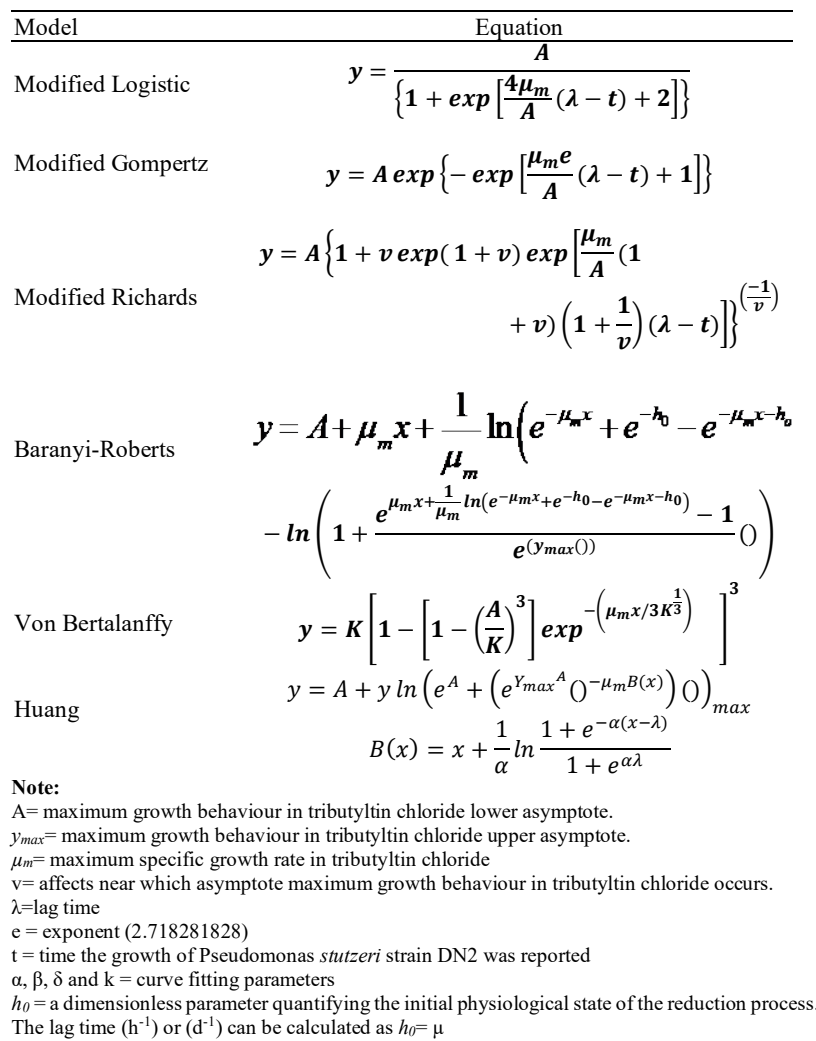




\section{RESULT AND DISCUSSION}

The primary Kinetics Modelling of Pseudomonas stutzeri strain DN2 growth behaviour in tributyltin chloride was presented in (Figs. 1 - 6), while the secondary kinetic modelling was presented in Figs. 7 - 11. All the seven primary models show best fitting for Pseudomonas strain DN2 growth behaviour in tributyltin chloride. The $R^{2}$ values which indicates the best fitting of a model for all the primary models was closer to unity (0.99). The modified logistics was considered to be the best model on the basis of adjusted $R^{2}$ values and low value of RMSE. The adjusted $R^{2}$ value for modified logistics 0.99 while the RMSE values was 0.14 . The modified logistic model was then utilized to model the growth profile at various concentrations of tributyl tin chloride.

Table 2. Statistical analysis of the various fitting primary models.

\begin{tabular}{lllllll}
\hline Model & $p$ & RMSE & $a d R 2$ & AF & BF & AICc \\
\hline Huang & 4 & 0.18 & 0.98 & 1.32 & 1.03 & 1.49 \\
Baranyi-Roberts & 4 & 0.14 & 0.98 & 1.18 & 1.08 & -2.45 \\
Modified Gompertz & 3 & 0.16 & 0.98 & 8.20 & 0.99 & -12.97 \\
Modified Richards & 4 & 0.15 & 0.98 & 1.56 & 1.44 & -1.34 \\
modified Logistics & 3 & 0.14 & 0.99 & 1.51 & 1.39 & -15.22 \\
von Bertalanffy & 4 & 0.17 & 0.98 & 1.21 & 1.11 & -11.46
\end{tabular}

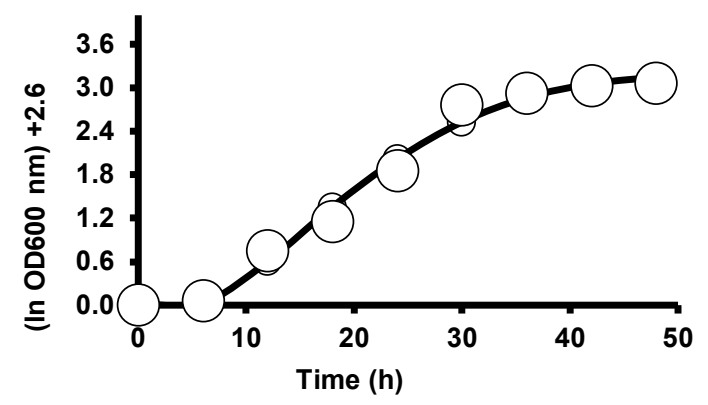

Fig. 1. Kinetics Modelling of Pseudomonas stutzeri strain DN2 growth behaviour in TBTCl using the Huang model.

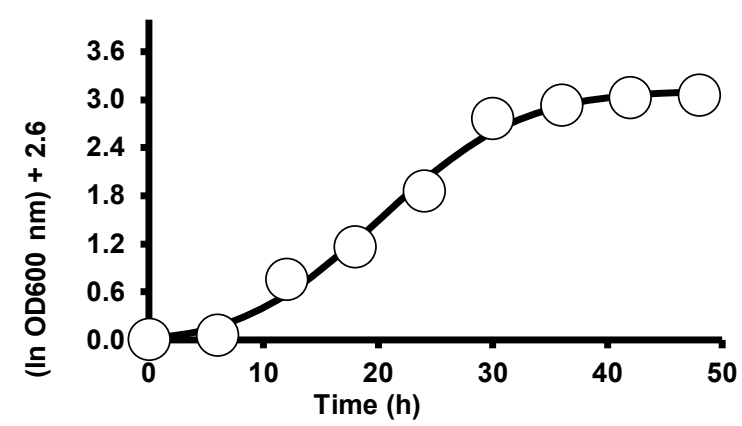

Fig. 2. Kinetics Modelling of Pseudomonas stutzeri strain DN2 growth behaviour in TBTCl using the Baranyi-Roberts model.

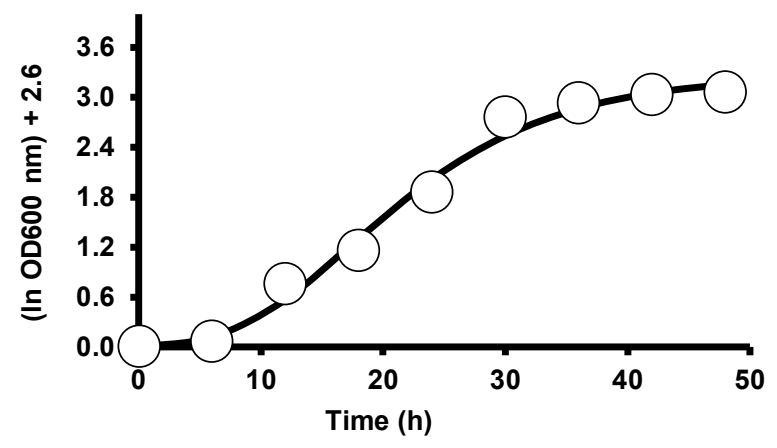

Fig. 3. Kinetics Modelling of Pseudomonas stutzeri strain DN2 growth behaviour in TBTCl using the modified Gompertz model.

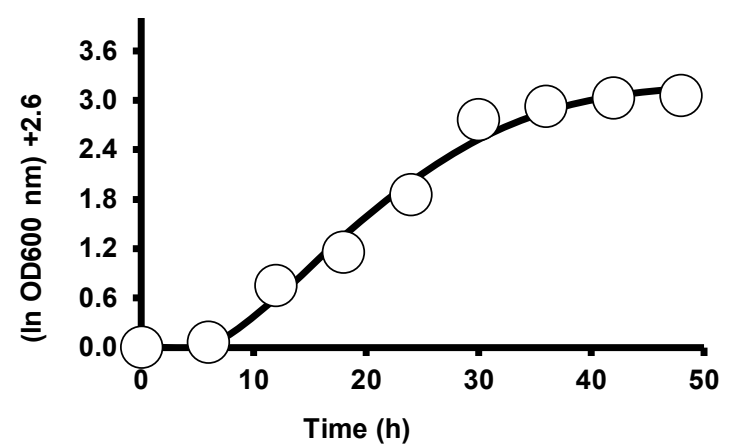

Fig. 4. Kinetics Modelling of Pseudomonas stutzeri strain DN2 growth behaviour in TBTCl using the modified Richard model.

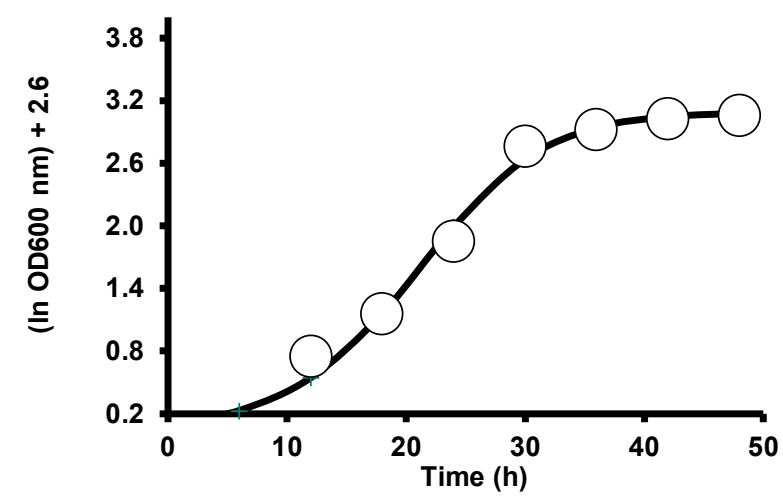

Fig. 5. Kinetics Modelling of Pseudomonas stutzeri strain DN2 growth behaviour in TBTCl using the modified logistics model. 


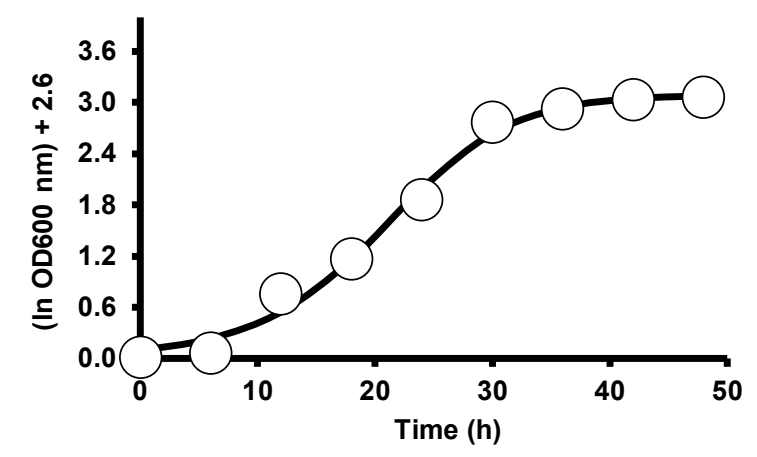

Fig. 6. Kinetics Modelling of Pseudomonas stutzeri strain DN2 growth behaviour in TBTCl using the von Bertalanffy model.

The accuracy and statistical analysis of all the secondary kinetic models used revealed that Monod, Haldane, Aiba, Yano and Luong were able to fit the data, with both the Aiba and Haldane being the best model with low RMSE and AICc (-12) values, highest adjusted $R^{2}$ values, closest to unity (1.0), (Table 4). Although many different growths rate formulae have been proposed in the literature, only a few are currently used.

The Haldane equation is the most popular rate expression for microorganisms in general [23-31] followed by the Aiba model $[25,26]$. Because most studies on the effects of toxic substrates on microbial growth use toxic substrates like aromatic and halogenated hydrocarbons, it's safe to infer that at high concentrations, growth rate will be significantly impeded, and other non-fitting models like Monod will fail. The Haldane model has been used to forecast a range of bacterial growths on xenobiotics and has been widely used as a general-purpose model for understanding substrate inhibition kinetics. The highest concentration at which cultures can sustain shock doses is known as the inhibition constant $\left(K_{i}\right)$. This is an extremely significant value.

Table 3. Secondary kinetic models used in this study.

\begin{tabular}{lcc}
\hline Model & Equation & Ref \\
\hline Monod & $\mu \frac{S}{K_{S}+S_{\max }}$ & {$[32]$} \\
Haldane & $\mu_{\max } \frac{S}{S+K_{S}+\frac{S^{2}}{K_{i}}}$ & \\
Aiba & $\mu \frac{S}{K_{S}+S} \exp (-K P)_{\max }$ & \\
& $\frac{\mu_{\max }}{S+K_{S}+\left(\frac{S^{2}}{K_{1}}\right)\left(1+\frac{S}{K}\right)}$ & \\
Yano & $\mu \frac{S}{S+K_{s}}\left[1-\left(\frac{S}{S_{m}}\right)^{n}\right]$ & \\
Luong & {$[33]$}
\end{tabular}

Table 4. Statistical analysis of the various fitting secondary models.

\begin{tabular}{llllll}
\hline Model & p RMSE & $\mathrm{adR}^{2}$ & $\mathrm{AICc}$ & $\mathrm{BF}$ & $\mathrm{AF}$ \\
\hline Luong & 40.0552 & 0.590 & 32 & 1.002 & 1.154 \\
Yano & 40.0552 & 0.590 & 32 & 1.002 & 1.154 \\
Aiba & 30.0478 & 0.726 & -12 & 1.002 & 1.154 \\
Haldane & 30.0478 & 0.726 & -12 & 1.002 & 1.154 \\
Monod & 20.0428 & 0.795 & -8 & 1.002 & 1.154
\end{tabular}

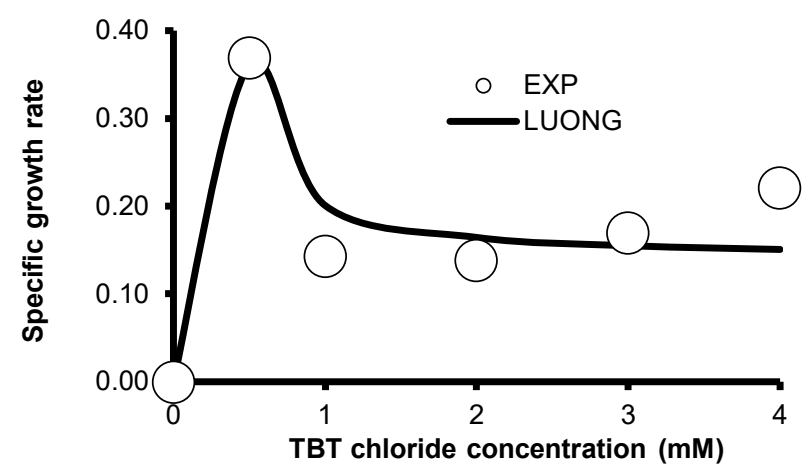

Fig. 7. Kinetics Modelling of Pseudomonas stutzeri strain DN2 growth behaviour in TBTCl using the Luong model.

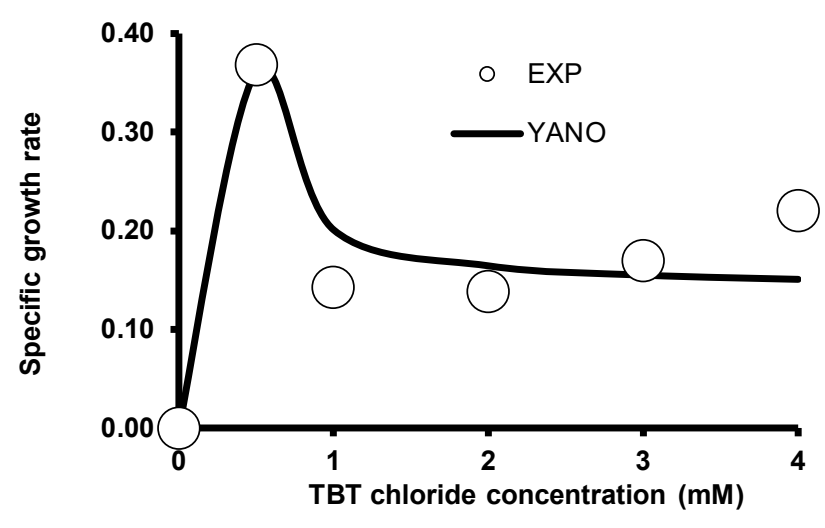

Fig. 8. Kinetics Modelling of Pseudomonas stutzeri strain DN2 growth behaviour in TBTCl using the Yano model.

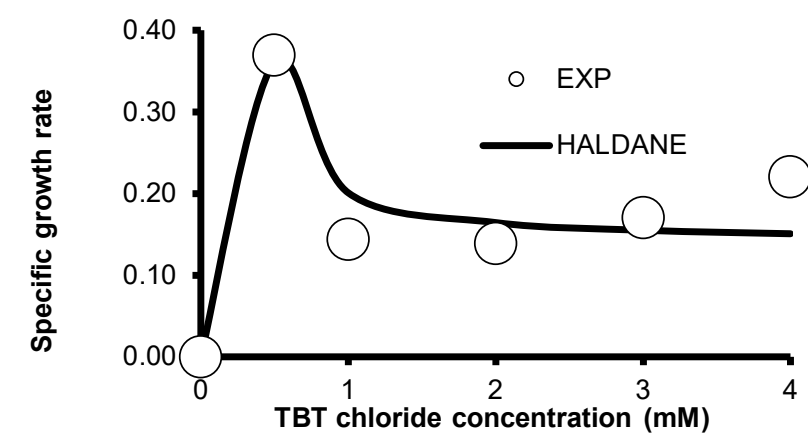

Fig. 9. Kinetics Modelling of Pseudomonas stutzeri strain DN2 growth behaviour in TBTCl using the Haldane model. 


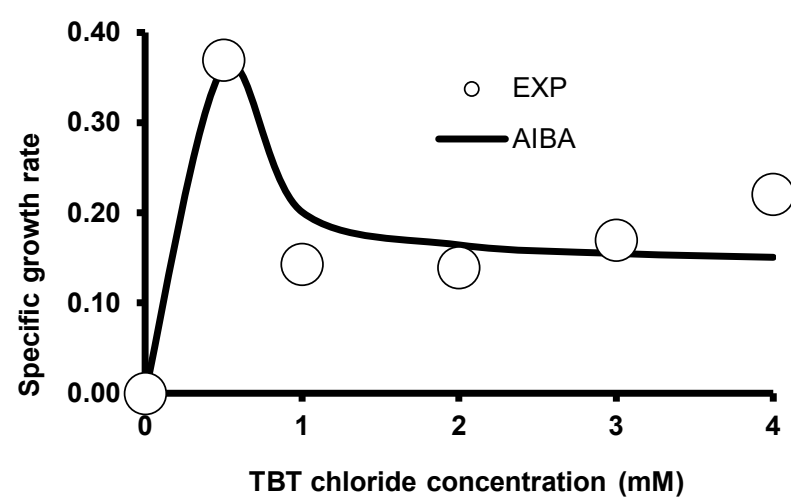

Fig. 10. Kinetics Modelling of Pseudomonas stutzeri strain DN2 growth behaviour in TBTCl using the Aiba model.

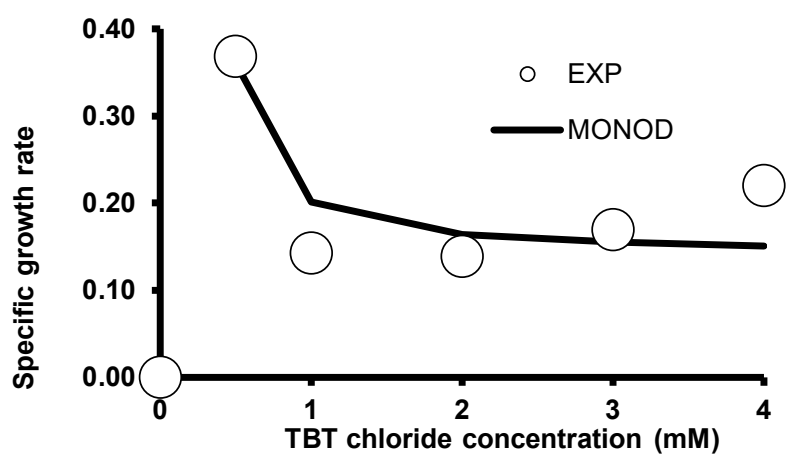

Fig. 11. Kinetics Modelling of Pseudomonas stutzeri strain DN2 growth behaviour in TBTCl using the Monod model.

\section{CONCLUSION}

Bacterial growth and degradation kinetics can be modelled using a variety of models available in the literature. A literature review revealed that multiple models for the same molecule have been shown to be optimal in different settings, hence a comprehensive modelling exercise involving primary and secondary model was carried based on existing published works to demonstrate this fact. In this paper, we show that the modified logistic and Monod models were the best fit for Pseudomonas stutzeri strain DN2 growth behaviour in tributyltin chloride.

\section{REFERENCES}

1. Yousif E. A Review of Organotin Compounds: Chemistry and Applications. Arch Org Inorg Chem Sci . 2018 Jul 17 [cited 2021 Sep 14];3(3).

2. Khanolkar DS, Naik MM, Dubey SK. Biotransformation of Tributyltin chloride by Pseudomonas stutzeri strain DN2. Braz J Microbiol . 2014 Dec [cited 2021 Sep 14];45(4):1239-45.

3. Marques VB, Faria RA, Dos Santos L. Overview of the Pathophysiological Implications of Organotins on the Endocrine System. Front Endocrinol . 2018 Mar 16 [cited 2021 Sep 14];9:101. Available from: http://journal.frontiersin.org/article/10.3389/fendo.2018.00101/full

4. Champ MA, Seligman PF. An Introduction to Organotin Compounds and Their Use in Antifouling Coatings. In: Champ MA, Seligman PF, editors. Organotin . Dordrecht: Springer Netherlands; 1996 [cited 2021 Sep 14]. p. 1-25.

5. Meng P, Wang J, Liu L, Chen M, Hung T. Toxicity and bioaccumulation of tributyltin and triphenyltin on oysters and rock shells collected from Taiwan maricuture area. Sci Total Environ 2005 Oct 15 [cited 2021 Sep 15];349(1-3):140-9. Available from: https://linkinghub.elsevier.com/retrieve/pii/S0048969705000525

6. Andersen KG, Rambaut A, Lipkin WI, Holmes EC, Garry RF. The proximal origin of SARS-CoV-2. Nat Med . 2020 Apr [cited 2020 Jul 23];26(4):450-2.

7. Kucharski D, Drzewicz P, Nałęcz-Jawecki G, Mianowicz K, Skowronek A, Giebułtowicz J. Development and Application of a Novel QuEChERS Method for Monitoring of Tributyltin and Triphenyltin in Bottom Sediments of the Odra River Estuary, North Westernmost Part of Poland. Molecules . 2020 Jan 29 [cited 2021 Sep 15];25(3):591.

8. Fickova M, Macho L, Brtko J. A comparison of the effects of tributyltin chloride and triphenyltin chloride on cell proliferation, proapoptotic p53, Bax, and antiapoptotic Bcl-2 protein levels in human breast cancer MCF-7 cell line. Toxicol In Vitro . 2015 Jun [cited 2021 Sep 15];29(4):727-31.

9. Hunakova L, Macejova D, Toporova L, Brtko J. Anticancer effects of tributyltin chloride and triphenyltin chloride in human breast cancer cell lines MCF-7 and MDA-MB-231. Tumor Biol . 2016 May [cited 2021 Sep 15];37(5):6701-8.

10. Wroński M. Application of tributyltin chloride to the separation and column chromatography of thiols. J Chromatogr A . 1976 Feb [cited 2021 Sep 15];117(1):47-52.

11. Cruz A, Anselmo AM, Suzuki S, Mendo S. Tributyltin (TBT): A Review on Microbial Resistance and Degradation. Crit Rev Environ Sci Technol . 2015 May 3 [cited 2021 Sep 16];45(9):9701006. 181

12. Takahashi S, Tanabe S, Takeuchi I, Miyazaki N. Distribution and Specific Bioaccumulation of Butyltin Compounds in a Marine Ecosystem. Arch Environ Contam Toxicol . 1999 Jul 1 [cited 2021 Sep 16];37(1):50-61.

13. Shamim K, Naik MM, Pandey A, Dubey SK. Isolation and identification of Aeromonas caviae strain KS-1 as TBTC- and leadresistant estuarine bacteria. Environ Monit Assess . 2013 Jun [cited 2021 Sep 16];185(6):5243-9.

14. Ayanda OS, Fatoki OS, Adekola FA, Ximba BJ. Fate and Remediation of Organotin Compounds in Seawaters and Soils. Chem Sci Trans . 2012 Aug 25 [cited 2021 Sep 16];1(3):470-81.

15. Clark EA, Sterritt RM, Lester JN. The fate of tributyltin in the aquatic environment. Environ Sci Technol . 1988 Jun [cited 2021 Sep 16];22(6):600-4.

16. Dowson PH, Bubb JM, Lester JN. Persistence and Degradation Pathways of Tributyltin in Freshwater and Estuarine Sediments. Estuar Coast Shelf Sci . 1996 May [cited 2021 Sep 16];42(5):55162 .

17. Suehiro F, Kobayashi T, Nonaka L, Tuyen BC, Suzuki S. Degradation of Tributyltin in Microcosm Using Mekong River Sediment. Microb Ecol . 2006 Jul [cited 2021 Sep 16];52(1):19-25.

18. Worldometer. COVID-19 Coronavirus Pandemic . 2020 [cited 2020 Jul 15]. Available from: https://www.worldometers.info/coronavirus/\#countries

19. Halmi MIE, Shukor MS, Johari WLW, Shukor MY. Modeling the growth curves of Acinetobacter sp. strain DRY12 grown on diesel. J Environ Bioremediation Toxicol. 2014;2(1):33-7.

20. Abdulrasheed M, Hussein II, Ahmad I, Namadina MM, Muhammad F, Ibrahim S. Growth mathematical modelling of the effect of Cyanide on Pseudomonas putida ( Naun-16 ). Bioremediation Sci Technol Res. 2020;8(1):27-31.

21. Motulsky HJ, Ransnas LA. Fitting curves to data using nonlinear regression: a practical and nonmathematical review. FASEB J Off Publ Fed Am Soc Exp Biol. 1987;1(5):365-74.

22. Ross T, McMeekin TA. Predictive microbiology. Int J Food Microbiol. 1994;23(3-4):241-64

23. Lodha B, Bhat P, Kumar MS, Vaidya AN, Mudliar S, Killedar DJ, et al. Bioisomerization kinetics of $\gamma-\mathrm{HCH}$ and biokinetics of Pseudomonas aeruginosa degrading technical $\mathrm{HCH}$. Biochem Eng J. 2007;35(1):12-9.

24. Othman AR, Yusof MT, Shukor MY. Biodegradation of Sodium Dodecyl Sulphate (SDS) by Serratia marcescens strain DRY6. Bioremediation Sci Technol Res. 2019 Dec 28;7(2):9-14. 
25. Karamba KI, Ahmad SA, Zulkharnain A, Yasid NA, Ibrahim S, Shukor MY. Batch growth kinetic studies of locally isolated cyanide-degrading Serratia marcescens strain AQ07. 3 Biotech . 2018 Jan [cited 2019 Jul 10];8(1). Available from: https://www.ncbi.nlm.nih.gov/pmc/articles/PMC5723573/

26. Manogaran M, Yasid NA, Ahmad SA. Mathematical modelling of glyphosate degradation rate by Bacillus subtilis. J Biochem Microbiol Biotechnol. 2017 Jul 31;5(1):21-5.

27. Jiang B, Li A, Cui D, Cai R, Ma F, Wang Y. Biodegradation and metabolic pathway of sulfamethoxazole by Pseudomonas psychrophila HA-4, a newly isolated cold-adapted sulfamethoxazole-degrading bacterium. Appl Microbiol Biotechnol. 2014;98(10):4671-81.

28. Dahalan FA, Yunus I, Johari WLW, Shukor MY, Halmi MIE, Shamaan NA, et al. Growth kinetics of a diesel-degrading bacterial strain from petroleum-contaminated soil. J Environ Biol. 2014;35(2):399-406.

29. Gan HM, Shahir S, Ibrahim Z, Yahya A. Biodegradation of 4aminobenzenesulfonate by Ralstonia sp. PBA and Hydrogenophaga sp. PBC isolated from textile wastewater treatment plant. Chemosphere. 2011;82(4):507-13.

30. Cheng Z-W, Gu X-N, Jiang Y-F, Chen J-M, Chen J. Isolation and identification of an alpha-pinene-degrading bacterium and its degradation characteristics. Zhongguo Huanjing KexueChina Environ Sci. 2011;31(4):622-30.

31. Sahinkaya E, Dilek FB. Modeling chlorophenols degradation in sequencing batch reactors with instantaneous feed-effect of 2,4DCP presence on 4-CP degradation kinetics. Biodegradation. 2007;18(4):427-37.

32. De Stefano L, Stepanov I, Abramson C. The First Order Transfer Function in the Analysis of Agrochemical Data in Honey Bees (Apis Mellifera L.): Proboscis Extension Reflex (PER) Studies. Insects . 2014 Jan 7 [cited 2021 Sep 23];5(1):167-98.

33. Bakhshi Z, Najafpour G, Kariminezhad E, Pishgar R, Mousavi N, Taghizade T. Growth kinetic models for phenol biodegradation in a batch culture of Pseudomonas putida. Environ Technol . 2011 Dec [cited 2021 Sep 23];32(16):1835-41.

34. Richards FJ. A Flexible Growth Function for Empirical Use. J Exp Bot . 1959 [cited 2021 Sep 23];10(2):290-301. 